\title{
Um Algoritmo Genético para Seleção de Portfólio de Investimentos com Restrições de Cardinalidade e Lotes-Padrão
}

\author{
Renan Fortes Tourinho, Antônio Costa de Oliveira, Rodrigo de Melo Souza Veras \\ ${ }^{1}$ Departamento de Computação (DC) - Universidade Federal do Piauí (UFPI) \\ Teresina - PI - Brasil \\ renantourinho@gmail.com, \{costa,rveras\}@ufpi.edu.br
}

\begin{abstract}
The Markowitz's quadratic model played a key role in the investments' portfolio selection problem, however, no longer meets the needs of the complexity of the current market. The addition of constraints to approximate the model to the real situation faced by investors, makes the problem NP-Complete. Thus, this paper presents a genetic algorithm that seeks to maximize the investment's return, given an acceptable risk level. After portfolio optimization based on historical data, there is a forecast for the subsequent year. The results improves the Bovespa index performance, highlighting the effects of diversification according to the number of assets and the capital available for investment.
\end{abstract}

Resumo. O modelo quadrático de Markowitz desempenhou um papel fundamental no problema da seleção de portfólio de investimentos, contudo, já não atende às necessidades da complexidade do mercado atual. A adição de restrições que aproximam o modelo à situação real enfrentada pelos investidores, tornam o problema NP-Completo. Assim, este artigo apresenta um Algoritmo Genético que busca maximizar o retorno de um investimento, dado um patamar aceitável de risco. Após a otimização do portfólio com base em dados históricos, faz-se uma previsão para o ano posterior. Os resultados superam a performance do Índice Bovespa, destacando os efeitos da diversificação de acordo com o número de ativos e com o capital disponível para investimento.

\section{Introdução}

Historicamente, a necessidade de otimizar os recursos, fez com que a seleção de portfólio se tornasse um tópico de amplo interesse aos fundos de investimento institucionais. Nos últimos anos esse assunto tem sido considerado no âmbito da gestão de carteiras de investidores individuais, com o objetivo de melhorar os resultados dos indivíduos, adaptando as melhores práticas já consolidadas no contexto institucional [Torre e Rudd 2004].

Para decidir a melhor combinação dentre as possibilidades de investimentos existentes, é necessário levar em conta tanto o retorno que será obtido como o risco que será incorrido. Nesse contexto, Harry Markowitz [Markowitz 1952] propôs um método para solucionar de maneira direta a escolha dos ativos para investimento, através da quantificação de variáveis outrora indefinidas, como o risco e o retorno do portfólio, o que deu origem à moderna teoria das carteiras. O modelo média-variância, como ficou conhecido, estima o retorno da carteira como a média ponderada de todos os retornos de cada ativo, enquanto o risco é mensurado pela variância da carteira escolhida. 
A importância deste trabalho consiste na otimização de portfólios que visam fornecer o melhor retorno para um patamar aceitável de risco, se utilizando de uma extensão do Modelo de Markowitz [Markowitz 1952]. Além disso considerou-se a inserção de duas restrições do mundo real, lotes-padrão mínimos para compra de cada ativo e número de ações diferentes (cardinalidade) para diversificação do investimento, investigando também os seus efeitos sobre o retorno obtido. Nesse caso, portfólio (ou carteira) refere-se a um conjunto de investimentos composto por um determinado número de ações. Segundo [Kellerer et al. 1999], este é um problema NP-Completo, em que desconhece-se um algoritmo polinomial que possa resolvê-lo.

Para lidar com tal complexidade, este trabalho apresenta um Algoritmo Genético (AG), utilizando como entrada dados históricos de cotações de ações da Bolsa de Valores, Mercadorias e Futuros de São Paulo (BM\&FBOVESPA) [Bovespa 2012], durante o ano 2010 no intuito de otimizar portfólios, e utilizá-los como investimento para o ano de 2011, comparando o desempenho da carteira obtida ao Índice Bovespa (IBOVESPA), o benchmark que melhor representa o comportamento do mercado brasileiro.

Este artigo está organizado da seguinte maneira: a seção 2 expõe o estado da arte das pesquisas relacionadas ao problema. Na seção 3, o problema e suas restrições são definidos, tendo sua modelagem detalhada na seção 4. A seção 5, por sua vez, define o Algoritmo Genético conforme seus principais operadores. A seção 6 é responsável por detalhar os experimentos empíricos realizados, enquanto a seção 7 discute os resultados computacionais obtidos. Na seção 8, por sua vez, é apresentada a conclusão e são discutidas algumas possibilidades de trabalhos futuros.

\section{Estado da Arte}

Markowitz [Markowitz 1952] definiu um framework quantitativo para a seleção de portfólios, ao alocar ativos dependentes das medidas de retorno e risco por ele propostas. A resolução de tais parâmetros resultou em um gráfico composto por uma lista de carteiras que associam seus retornos para um mínimo risco possível, ou seu risco para um máximo retorno almejado, nomeado como Fronteira Eficiente. Posteriormente, William Sharpe [Sharpe 1963] simplificou a função de Markowitz, formando o Modelo de Índice Único, que deu origem ao Modelo de Precificação de Ativos Financeiros (CAPM).

Como desenvolvimento alternativo, Hiroshi Konno e Hiroaki Yamazaki [Konno e Yamazaki 1991] foram os responsáveis pela utilização do desvio-médio absoluto como medida de risco, consolidando um modelo de programação linear. Em [Markowitz et al. 1993], os autores, por sua vez, estudaram funções objetivas mais complexas, e propuseram outras soluções baseadas no conceito de semivariância. Tais modelos oferecem uma robusta fundamentação teórica, contudo, compartilham da fraqueza de simplificar o cenário enfrentado pelo investidor, o que os distancia de uma solução com real aplicação prática em um ambiente de mercado.

Uma característica marcante dos portfólios financeiros diz respeito à diversificação de ativos, onde a inclusão de novos investimentos diminuem o risco diversificável ao passo que aumentam o retorno esperado. Tal premissa leva o investidor a querer maximizar a relação entre o retorno e o risco incluindo o máximo de ativos possíveis em sua carteira. Todavia, Maringer [Maringer 2005] mostrou que a maior parte dos efeitos positivos da diversificação pode ser obtida sem necessitar envolver todas as 
ações disponíveis no mercado.

À medida que os pesquisadores buscavam aproximar os portfólios otimizados da realidade, mais restrições foram consideradas. Portfólios com limites mínimos de compra foram considerados em [Beale e Forest 1976], buscando evitar o investimento de pequenas parcelas do capital em um único ativo.

Para explorar o impacto da diversificação ou de taxas sobre investimentos, a restrição de cardinalidade começou a ser inserida nos modelos, permitindo ao investidor comprar apenas um número pré-definido de ações. [Chang et al. 2000] consideraram uma fronteira eficiente descontínua ao adicionar determinados números de ativos para formação de carteiras. [Li et al. 2006] abordaram a restrição de cardinalidade juntamente a lotes específicos, adaptados para a realidade do mercado de Hong Kong.

Através de uma formulação de programação quadrática inteira-mista, [Corazza e Favaretto 2007] buscaram soluções viáveis através de um número finito de passos, simulando portfólios com 5, 10, 25, 50, 100 e 250 ativos. Ainda considerando a cardinalidade, [Shaw et al. 2008] apresentaram um procedimento baseado em um relaxamento lagrangeano, simplificando a matriz de covariância em uma matriz de risco diagonal, reduzindo o tempo computacional da resolução do modelo, mas também sua expressividade quanto às restrições.

Utilizando a heurística Simulated Annealing, [Derigs e Nickel 2003] consideraram variáveis macroeconômicas para influenciar no risco e retorno de seu modelo, aplicado ao mercado alemão. [Cura 2009] apresentou um modelo baseado em particle swarm optimisation, onde cada partícula representava um portfólio, com resultados baseados nos problemas-teste provenientes de [Chang et al. 2000].

Por intermédio de uma Busca Tabu híbrida, [Junior et al. 2011] resolveram um modelo estendido de Markowitz, considerando lotes-padrão e custos de transação associados à BM\&FBOVESPA, contudo, ignorando a cardinalidade. [Raposo 2010] utiliza dois Algoritmos Genéticos (AGs), um para agrupamento e outro para seleção de ativos, a fim de também resolver o modelo de Markowitz e aplicá-lo à Bolsa de Valores, limitando-se à formação de conjuntos através de similaridades e divergências em relação aos retornos das ações avaliadas. Ainda no mercado brasileiro, [Freitas e Ribeiro 2009] otimizaram portfólios com base no conceito de Valor em Risco Condicional (CVAR), utilizando-se de um modelo de programação linear para representação do problema, contudo, sem forte representação do cenário real enfrentado pelos investidores.

\section{Seleção de portfólio de investimentos com restrições de cardinalidade e lotes-padrão}

Para a seleção de investimentos, o ideal seria considerar o retorno e risco esperados. Contudo, pela enorme dificuldade em se obter esses valores esperados, uma estimativa comum para risco e retorno esperados vem da avaliação da média e volatilidade do seu retorno histórico, de modo que, implicitamente, é suposto que o passado vai repetir-se no futuro.

Restrição de Lotes-Padrao: para prover liquidez ao mercado financeiro, os ativos são transacionados em múltiplos de quantidades mínimas, conhecidos como lotes. Ao inserir tal restrição, o problema passa a ter uma região de viabilidade descontínua [Lin e Liu 2007]. 
Restrição de Cardinalidade: Markowitz [Markowitz 1952] mostrou que a diversificação de investimentos diminui o risco do portfólio, todavia, não há um consenso para definir quantos tipos de ações diferentes são suficientes para que haja uma redução significativa no risco, sem afetar consideravelmente o retorno. [Evans e Archer 1968] explicam que 10 ativos reduzem o risco praticamente na mesma proporção que se o capital fosse diversificado em todo o mercado. No entanto, a metodologia utilizada por Evans é questionada por [Bird e Tippett 1986], pelo argumento de que os parâmetros de Mínimos Quadrados utilizados eram tendenciosos e, consequentemente, ainda há um benefício considerável de redução de risco ao se expandir mais o tamanho da carteira.

A abordagem heurística encontrou espaço na otimização de portfólios com restrições, primeiramente através do trabalho de [Chang et al. 2000], que propôs soluções através de Algoritmos Genéticos, Busca Tabu e Simulated Annealing, expondo as diferenças no formato da fronteira eficiente, que exibe o melhor retorno para um dado patamar de risco, de acordo com um número pré-definido de ações a serem escolhidas.

\section{Modelo de Markowitz Estendido}

O modelo de Markowitz, onde o retorno de um portfólio é definido pela média ponderada dos retornos individuais de cada ação, e o risco é mensurado pela soma das variâncias dos ativos e das covariâncias entre todos os ativos, é um modelo quadrático de decisão multi-objetivo que visa maximizar o lucro enquanto reduz o risco [Markowitz 1959]. Por conveniência, este modelo usualmente fixa um de seus objetivos para trabalhar a otimização do outro, portanto, o trabalho abordará a maximização do retorno para um determinado patamar de risco ao qual o investidor está disposto a aceitar. Para que os resultados tornem-se mais próximos da realidade, o modelo será estendido pela adição de restrições quanto à quantidade máxima e mínima de investimento percentual em uma única ação, assim como as restrições de cardinalidade e lotes-padrão.

\section{Modelo de Markowitz Estendido}

$$
\max R_{p}=\sum_{i=1}^{n} w_{i} r_{i}
$$

Sujeito a:

$$
\begin{aligned}
& \sigma_{p}^{2}=\sum_{i=1}^{n} \sum_{j=1}^{n} w_{i} w_{j} \sigma_{i j} \\
& w_{i} \geq 0 \\
& w_{i}=\frac{x_{i} c_{i}}{\sum_{i=1}^{n} x_{i} c_{i}}, i=(1,2, \cdots, n) \\
& \sum_{i=1}^{n} x_{i} c_{i} \leq b \\
& \sum_{i=1}^{n} z_{i}=k \text { onde }\left\{\begin{array}{l}
z_{i}=1, \quad \text { caso a ação seja selecionada } \\
z_{i}=0, \text { caso contrário }
\end{array}\right. \\
& L_{\text {inf }} *\left(1-z_{i}\right) \leq x_{i} c_{i} \leq L_{\text {sup }_{i}} *\left(1-z_{i}\right)
\end{aligned}
$$

As equações (1)-(3) representam o modelo original de Markowitz, onde $n$ é o numero de ações, $R_{p}$ é a taxa total esperada do retorno; $r_{i}$ é a taxa de retorno esperada 
para a ação $i ; \sigma_{i j}$ representa a covariância entre as ações $i$ e $j ; \sigma_{p}^{2}$ é a variância do portfólio; $p$ é o patamar de risco aceitável ao investidor. $w_{i}$ representa a fração (ou peso) do capital investido no ativo $i$. Na equação (4), $x_{i}$ é o número de lotes-padrão do ativo $i$, que vai compor o portfólio. $c_{i}$ representa o preço da ação $i$. $z_{i}$ é uma variável binária para garantir a cardinalidade. $k$ representa o número de ações que formarão a carteira e $L_{i n f_{i}}$ e $L_{s u p_{i}}$ são, respectivamente, o mínimo e o máximo investimento permitido em um único ativo $i$.

A equação (4) expressa a conversão dos valores reais de investimento em uma medida percentual do capital disponível. A equação (5), por sua vez, garante que a carteira formada não extrapole o orçamento. Em (6), garante-se que exatamente $k$ ativos formarão o portfólio, já na equação (7), há uma limitação para evitar um investimento muito baixo ou muito alto em uma única ação, dependendo do capital total disponível.

\section{Algoritmo Genético Proposto}

Atualmente, uma grande variedade de problemas de otimização tem sido enfrentada por técnicas heurísticas devido à dificuldade de resolução por métodos exatos [Pham e Karaboga 2000]. Dentre as heurísticas de melhor desempenho, destacam-se os Algoritmos Genéticos. Originalmente proposto por [Holland 1975], Algoritmo Genético é uma técnica de busca baseada nos mecanismos de seleção natural. Eles usam como base a mesma ideia que rege o seguinte princípio que existe na natureza: a sobrevivência dos mais aptos. Sua utilização tem sido cada vez mais explorada principalmente pela robustez e simplicidade que oferece [Gen e Cheng 1997].

A maioria das técnicas heurísticas iniciam a busca com uma solução inicial para o problema. Essa solução é progressivamente modificada, na busca de uma solução ótima ou próxima da ótima. Os Algoritmos Genéticos, por sua vez, transformam uma população de possíveis soluções em uma nova geração de soluções usando os princípios Darwinianos de reprodução e sobrevivência dos mais aptos, pela aplicação de determinadas etapas como codificação/decodificação, função de avaliação, seleção, cruzamento e mutação.

Codificação e Decodificação: Apesar do modelo proposto apresentar soluções inteiras, a codificação do AG se dá através de números reais, envolvendo a parcela $w_{i}$ do capital, ao invés das unidades padrão $x_{i}$. Para inicializar um cromossomo pertencente a uma população inicial, gera-se um $w_{i}$ aleatório, entre 0 e 1, para cada gene. Não é sempre que sempre a soma de todos os $w_{i}$ ficará igual ou menor a 1 , o que faz necessário uma normalização conforme a equação (8), onde $w_{i}^{\prime}$ é o novo peso normalizado.

$$
w_{i}^{\prime}=\frac{w_{i}}{\sum_{i=1}^{n} w_{i}}, i=(1,2, \cdots, n)
$$

Função de Avaliação: após a geração da população inicial, os cromossomos são avaliados segundo a sua função de avaliação, que é a representação da função objetivo. Aqui consiste um dos grandes problemas dos Algoritmos Genéticos aplicados a problemas com várias restrições: a inviabilidade das soluções. [Gen e Cheng 1997] propuseram três métodos para lidar com as restrições: rejeição, reparação e penalização.

A estratégia de rejeição descarta automaticamente uma solução inviável, gerando outra solução até que uma viável seja encontrada. Já a estratégia de reparação, transforma soluções inviáveis em viáveis e, por conta da dificuldade de adaptação aos proble- 
mas, ainda é pouco utilizada. Nesse trabalho, consideramos a estratégia de penalização, que formula uma função de penalização que aplica-se a todas as soluções inviáveis, na esperança de, quando submetidas aos processos de cruzamento e mutação, gerar proles viáveis. Em (9), $q_{i}$ é uma representação em número real, da quantidade de lotes-padrão adquiridos pelo peso $w_{i}^{\prime}$ de investimento no ativo $i$.

$$
\begin{gathered}
q_{i}=\frac{b * w_{i}}{c_{i}} \\
p\left(x_{i}\right)= \begin{cases}q_{i}-\bmod \left(q_{i}\right)+1, & \text { caso } \bmod \left(q_{i}\right) \geq 0,6 \\
q_{i}-\bmod \left(q_{i}\right), & \text { caso contrário }\end{cases}
\end{gathered}
$$

Em (10), a penalização gera a viabilização parcial da solução, uma vez que $x_{i}$ passa a ser representado de forma inteira, porém não é garantida que a soma de todos os investimentos sejam inferiores a $b$. A viabilização total com o objetivo de satisfazer a equação (5), será realizada apenas na última população, para aumento de eficiência.

Seleção: o operador de seleção, seleciona os indivíduos que sofrerão cruzamento e mutação. Da mesma forma que ocorre no processo de seleção natural, os indivíduos mais qualificados, de acordo com a função de avaliação, têm mais chances de serem escolhidos.

Para este estudo, foram testados a seleção por Torneio, por Roleta Viciada, e por Torneio Estocástico, sendo esse último método o que se mostrou mais promissor. Neste método, a cada geração a população é submetida a uma seleção aleatória de $y$ indivíduos ( $y$ é o tamanho do torneio). Posteriormente, monta-se uma Roleta Viciada, com proporções de acordo com a função de avaliação de cada um desses indivíduos, e um sorteio é efetuado para selecionar o candidato à próxima etapa, o cruzamento.

Cruzamento: o objetivo do cruzamento é a permutação de material genético entre os pares de indivíduos previamente selecionados. O cruzamento é o operador responsável pela recombinação de características dos pais durante a reprodução, permitindo que as próximas gerações herdem essas características.

Após definir o critério de seleção, testamos quatro tipos de cruzamentos: 1 ponto, 2 pontos, uniforme e $R^{3}$, tendo este último apresentado os melhores resultados. O cruzamento $R^{3}$ foi adaptado tendo como base o operador homônimo descrito em [Radcliffe 1991]. Suas regras consistem em verificar se ambos os pais possuem uma ação particular em seu portfólio. Em caso afirmativo, o filho resultante possuirá a mesma ação, em uma quantidade aleatória gerada entre o percentual desse ativo em cada um dos pais. Caso ambos os pais não possuam determinada ação em seus portfólios, ela também não constará na carteira de seus filhos. Por fim, se um determinado ativo consta em um pai, mas não em outro, o valor a ser repassado a seus filhos vai ser gerado aleatoriamente entre as quantidades de seus pais. De forma dinâmica, há uma função que varre todo o cromossomo após o cruzamento, visando transformar qualquer prole inviável em viável, segundo as restrições já definidas.

Mutação é a inserção de material genético novo na população. Este processo ocorre, de acordo com uma dada probabilidade de mutação. Esta perturbação no cromossomo é uma arma poderosa para tentar evitar que o algoritmo fique preso em ótimos locais. Neste experimento, a mutação ocorre através da escolha de um gene aleatório, 
dentre os $n$ genes considerados no cromossomo. O ativo escolhido tem seu número de lotes padrão modificado, obedecendo às mesmas restrições de normalização supracitadas, visando obter sempre cromossomos viáveis de real aplicação.

Elitismo: no intuito de garantir que o AG tenha sempre uma qualificação progressiva em suas soluções, surgiu o elitismo, que consiste em preservar os $x$ melhores indivíduos de uma geração, para as gerações seguintes, garantindo, no pior caso, que a próxima geração tenha o melhor resultado ao menos igual ao de seus pais [Coley 1999].

\section{Experimentos Empíricos}

Os estudo se utilizou de dados da BM\&FBOVESPA no período de 2010, considerando as ações que compõem o Índice Bovespa. Para fins de preservar a integridade das medidas de retorno e risco, desconsiderou-se as empresas que sofreram fusão, ou que não participaram do IBOVESPA durante todo o período estudado. Desse modo, os experimentos foram feitos sobre 40 empresas distintas, unificando a composição de ações ordinárias e preferenciais de uma mesma companhia.

O presente trabalho utiliza uma versão estendida do modelo de Markowitz. O objetivo é comparar o desempenho do portfólio otimizado à performance do Índice Bovespa, que é o mais importante indicador do desempenho médio das cotações do mercado de ações brasileiro. Sua relevância advém do fato de retratar o comportamento dos principais papéis negociados na BM\&FBOVESPA e também de sua tradição, pois o índice manteve a integridade de sua série histórica e não sofreu modificações metodológicas desde sua implementação em 1968 [Bovespa 2012].

O investimento em fundos indexados ao Ibovespa normalmente é preferível àqueles investidores que visam o longo prazo, uma vez que o capital é sujeito a volatilidades que podem resultar em perdas no curto prazo, mas historicamente tem se mostrado rentável no longo prazo, como pode-se perceber na Figura 1, onde o eixo das abscissas corresponde ao período histórico do índice, enquanto o eixo das ordenadas mostra a variação percentual e o valor da carteira teórica formada pelas ações que compõem o Ibovespa. Portanto, os resultados tem essencialmente o caráter comparativo à real variação do Ibovespa, ou seja, o objetivo não é que absolutamente haja lucro ao investidor individual a cada portfólio gerado, mas que relativamente a carteira formada supere continuamente o índice para gerar uma maior rentabilidade no longo prazo.

Para medir o retorno e o risco, foram consideradas as variações mensais dos preços das ações abordadas. A otimização dos portfólios, através do Algoritmo Genético proposto, ocorre sobre o horizonte de tempo de 1 ano (2010). Um portólio de investimentos é gerado para esse período, e posteriormente são considerados como investimentos para o ano de 2011, como se não houvesse conhecimento prévio dos resultados reais desse ano.

\subsection{Parâmetros utilizados}

Para determinar os melhores parâmetros para o Algoritmo Genético, o testamos para 600, 700, 800, 900 e 1000 gerações, onde o ponto de convergência aproximou-se das 800 gerações, sendo este o número escolhido. Para compor o número de portfólios em cada população, testou-se casos com 20, 30, 40 e 50 carteiras. Os melhores resultados vieram com 50 portfólios. Como limites percentuais superior e inferior de investimento em uma única ação, definimos a taxa de 0,5 e 0,02 , respectivamente. 


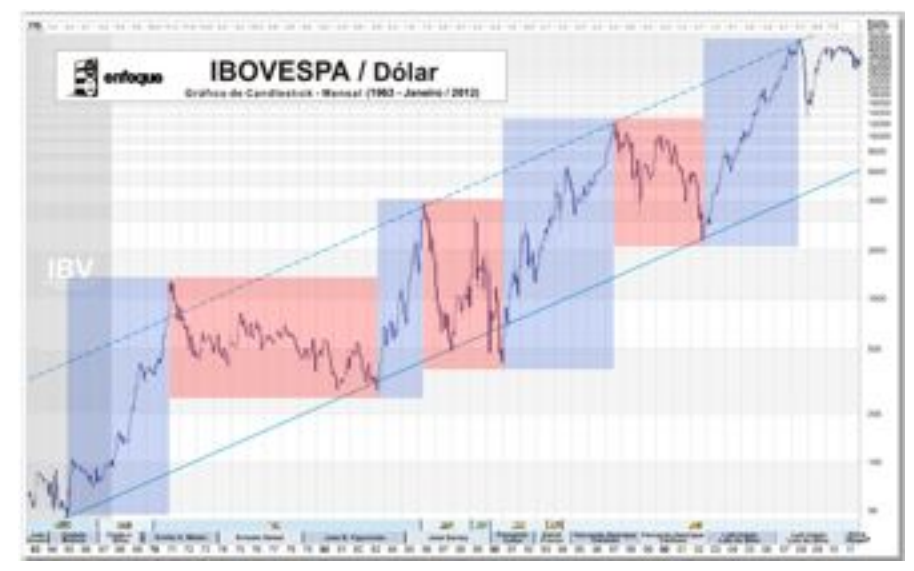

Figura 1. Gráfico Histórico lbovespa

As taxas probabilística de cruzamento variaram entre 0,8, 0,9 e 1; tendo apresentado um melhor resultado com a última taxa.Com o operador de mutação, foram testadas as taxas de $0,01,0,05,0,1$ e 0,2 , escolhendo-se a taxa de 0,1 . O número de soluções preservadas pelo elitismo variou entre 1, 3 e 5. Escolhendo-se o último valor. Como já citado, a seleção ocorre por intermédio do torneio estocástico, com $y=3$, o cruzamento se dá pelo modelo $R^{3}$ e a mutação acontece pela mudança de um gene.

Este trabalho contemplará os lotes-padrão de 100 ações, como sendo a unidade atômica de cada ativo, concordando com os lotes de negociação da BM\&FBOVESPA. Para verificar os efeitos da diversificação na função objetivo e sua relação com o capital disponível para investimento, foi considerada como restrição de cardinalidade portfólios de 10, 15, 10, 25 e 30 ações. Quanto ao capital inicial $b$ investido, analisou-se instâncias nos valores de $\mathrm{R} \$ 300.000,00, \mathrm{R} \$ 500.000,00, \mathrm{R} \$ 700.000,00$ e $\mathrm{R} \$ 1.000 .000,00$.

\section{Resultados Computacionais}

As instâncias foram executadas em um computador com processador Intel Core-I5 M430 com 2.27GHz, e 4GB de memória Ram, através do Sistema Operacional Windows 7. O tempo computacional mostrou-se satisfatório, com o menor tempo medindo 20 segundos, e o maior marcando 31 segundos. Cada instância foi executada 10 vezes, obtendo-se o melhor resultado dentre elas, assim como o resultado médio de todas as execuções.

Os resultados foram subdivididos e apresentados nas Tabelas 1, 2, 3, 4 de acordo com o montante investido em cada carteira. Cada tabela demonstra nas colunas 2 e 3 o portfólio otimizado através dos dados históricos de 2010, período no qual o Ibovespa teve um rendimento médio mensal de $-1,78 \%$; já nas colunas 4 e 5 , exibem o retorno, caso o investidor decidisse investir nesse mesmo portfólio otimizado, durante todo o período de 2011, sem conhecimento prévio de seus dados, apenas em posse dos preços de compra das ações no início do ano. Em 2011, semelhante ao ano anterior, o índice Bovespa também resultou em um retorno negativo, dessa vez em uma taxa de $-1,62 \%$ mensais.

O Ibovespa teve um rendimento médio mensal de $-1,78 \%$ em 2010 e de $-1,62 \%$ no período de 2011, resultando em prejuízo em ambos os anos. A heurística desenvolvida não alcança um saldo positivo na otimização ou na previsão, por trabalhar exclusivamente com ações que compõem o Ibovespa. Todavia, cumpre satisfatoriamente o seu objetivo 
Tabela 1. Percentual de lucro sobre capital investido de $\mathbf{R} \$ 300.000,00$

\begin{tabular}{|c|l|l|l|l|}
\hline & \multicolumn{2}{|c|}{ Portfólio Otimizado } & \multicolumn{2}{c|}{ Previsão para 2011 } \\
\hline Número de Ações do Portfólio & $\begin{array}{l}\text { Melhor } \\
\text { Retorno }\end{array}$ & $\begin{array}{l}\text { Retorno } \\
\text { Médio }\end{array}$ & $\begin{array}{l}\text { Melhor } \\
\text { Retorno }\end{array}$ & $\begin{array}{l}\text { Retorno } \\
\text { Médio }\end{array}$ \\
\hline 10 Ações & $\mathbf{- 0 . 1 3 \%}$ & $\mathbf{- 0 , 8 3 \%}$ & $\mathbf{0 , 1 \%}$ & $-0,77 \%$ \\
\hline 15 Ações & $-0,85 \%$ & $-1,33 \%$ & $-0,15 \%$ & $\mathbf{- 0 , 5 5 \%}$ \\
\hline 20 Ações & $-1,05 \%$ & $-1,56 \%$ & $-0,69 \%$ & $-1,16 \%$ \\
\hline 25 Ações & $-1,13 \%$ & $-1,68 \%$ & $-0,76 \%$ & $-1,39 \%$ \\
\hline 30 Ações & $-1,52 \%$ & $-1,91 \%$ & $-1,16 \%$ & $-1,84 \%$ \\
\hline
\end{tabular}

Tabela 2. Percentual de lucro sobre capital investido de $\mathbf{R} \$ \mathbf{5 0 0 . 0 0 0 , 0 0}$

\begin{tabular}{|c|l|l|l|l|}
\hline & \multicolumn{2}{|c|}{ Portfólio Otimizado } & \multicolumn{2}{c|}{ Previsão para 2011 } \\
\hline Número de Ações do Portfólio & $\begin{array}{l}\text { Melhor } \\
\text { Retorno }\end{array}$ & $\begin{array}{l}\text { Retorno } \\
\text { Médio }\end{array}$ & $\begin{array}{l}\text { Melhor } \\
\text { Retorno }\end{array}$ & $\begin{array}{l}\text { Retorno } \\
\text { Médio }\end{array}$ \\
\hline 10 Ações & $\mathbf{- 0 , 3 7 \%}$ & $\mathbf{- 0 , 9 9 \%}$ & $-0,57 \%$ & $-1,32 \%$ \\
\hline 15 Ações & $-0,45 \%$ & $-1,40 \%$ & $-0,37 \%$ & $\mathbf{- 0 , 9 8 \%}$ \\
\hline 20 Ações & $-0,95 \%$ & $-1,49 \%$ & $\mathbf{0 , 1 2 \%}$ & $-1,04 \%$ \\
\hline 25 Ações & $-1,42 \%$ & $-1,92 \%$ & $-0,47 \%$ & $-1,54 \%$ \\
\hline 30 Ações & $-1,79 \%$ & $-2,07 \%$ & $-0,86 \%$ & $-1,64 \%$ \\
\hline
\end{tabular}

Tabela 3. Percentual de lucro sobre capital investido de $\mathbf{R} \$ \mathbf{7 0 0 . 0 0 0 , 0 0}$

\begin{tabular}{|c|l|l|l|l|}
\hline & \multicolumn{2}{|c|}{ Portfólio Otimizado } & \multicolumn{2}{c|}{ Previsão para 2011 } \\
\hline Número de Ações do Portfólio & $\begin{array}{l}\text { Melhor } \\
\text { Retorno }\end{array}$ & $\begin{array}{l}\text { Retorno } \\
\text { Médio }\end{array}$ & $\begin{array}{l}\text { Melhor } \\
\text { Retorno }\end{array}$ & $\begin{array}{l}\text { Retorno } \\
\text { Médio }\end{array}$ \\
\hline 10 Ações & $\mathbf{0 , 0 9 \%}$ & $\mathbf{- 0 , 7 7 \%}$ & $-0,84 \%$ & $-1,36 \%$ \\
\hline 15 Ações & $-1,19 \%$ & $-1,46 \%$ & $\mathbf{- 0 , 3 3 \%}$ & $\mathbf{- 0 , 9 8 \%}$ \\
\hline 20 Ações & $-0,91 \%$ & $-1,67 \%$ & $-0,45 \%$ & $-1,09 \%$ \\
\hline 25 Ações & $-1,23 \%$ & $-1,95 \%$ & $-1,19 \%$ & $-1,63 \%$ \\
\hline 30 Ações & $-1,54 \%$ & $-1,91 \%$ & $-1,18 \%$ & $-1,56 \%$ \\
\hline
\end{tabular}

Tabela 4. Percentual de lucro sobre capital investido de $\mathbf{R} \$ \mathbf{1 . 0 0 0 . 0 0 0 , 0 0}$

\begin{tabular}{|c|l|l|l|l|}
\hline & \multicolumn{2}{|c|}{ Portfólio Otimizado } & \multicolumn{2}{|c|}{ Previsão para 2011 } \\
\hline Número de Ações do Portfólio & $\begin{array}{l}\text { Melhor } \\
\text { Retorno }\end{array}$ & $\begin{array}{l}\text { Retorno } \\
\text { Médio }\end{array}$ & $\begin{array}{l}\text { Melhor } \\
\text { Retorno }\end{array}$ & $\begin{array}{l}\text { Retorno } \\
\text { Médio }\end{array}$ \\
\hline 10 Ações & $\mathbf{- 0 , 5 5 \%}$ & $\mathbf{- 1 , 2 4 \%}$ & $-0,23 \%$ & $-1,40 \%$ \\
\hline 15 Ações & $-0,72 \%$ & $-1,38 \%$ & $\mathbf{0 , 1 0 \%}$ & $\mathbf{- 0 , 2 3 \%}$ \\
\hline 20 Ações & $-1,13 \%$ & $-2,00 \%$ & $-0,63 \%$ & $-1,04 \%$ \\
\hline 25 Ações & $-1,41 \%$ & $-2,14 \%$ & $-0,73 \%$ & $-1,19 \%$ \\
\hline 30 Ações & $-1,67 \%$ & $-2,46 \%$ & $-0,90 \%$ & $-1,51 \%$ \\
\hline
\end{tabular}

de superar o índice, uma vez que o objetivo da carteira é o lucro a longo prazo, seguindo a tendência exibida na Figura 1. No geral, os melhores resultados para a otimização foram obtidos com os portfólios de 10 e 15 ações.

Os resultados mais promissores para a previsão envolvendo 2011 encontram-se na seleção de carteiras com 15 ativos. A Tabela 4, por exemplo, mostra que se o investi- 
dor decidisse comprar papéis no primeiro dia do ano, baseado no portfólio de 15 ativos, otimizado do ano anterior, e decidisse vendê-lo no último dia do ano de 2011, teria uma média de perda de $0,23 \%$ ao mês. O melhor caso encontra-se na Tabela 2, onde, com 20 ativos, o investidor seria capaz de obter um lucro de $0,12 \%$ mensais, durante o ano de 2011, enquanto o Ibovespa sofreria com o prejuízo de $-1,62 \%$.

Quantos aos efeitos da diversificação, os experimentos mostraram sua influência na diminuição do retorno das carteiras, à medida que novos tipos de ativos eram acrescentados. Também observou-se que o aumento no orçamento disponível potencializou a queda no retorno, em função do aumento na cardinalidade, conforme expresso na Figura 2 , onde o maior capital investido ( $\mathrm{R} \$ 1.000 .000,00)$ gerou também o maior prejuízo ( $-2,46 \%$ com 30 ações), enquanto o menor orçamento $(R \$ 300.000,00)$ resultou na menor onerosidade ( $-1,91 \%$ com 30 ações). Isso deve-se ao fato do algoritmo ser obrigado a designar uma maior parcela do capital a ações que tiveram um desempenho indesejável durante o período analisado, a fim de obedecer a todas as restrições impostas.

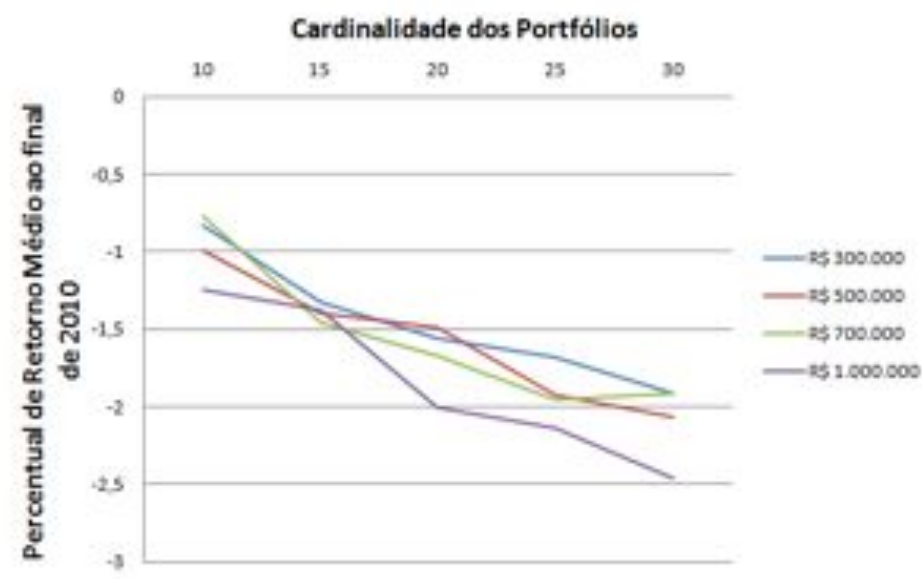

Figura 2. Efeitos da diversificação e do capital disponível, sobre o retorno dos portfólios

\section{Conclusão e Trabalhos Futuros}

A utilização de Algoritmos Genéticos para a otimização de carteiras considerando as restrições de cardinalidade e lotes-padrão, mostra-se eficiente e eficaz, encontrando soluções superiores ao benchmark, em todas as carteiras médias com até 15 ativos e na maioria dos portfólios médios com até 25 investimentos. O AG também superou o Ibovespa em todas as previsões para 2011, tornando o método viável para a utilização de um investidor que vise o longo prazo, ou até mesmo no auxílio de gestores institucionais que visam melhorar a rentabilidade de seus fundos indexados ao Índice Bovespa.

Quanto ao efeito da diversificação, os experimentos comprovam que, na maioria dos casos, o aumento no número de ativos dificulta a otimização do portfólio, trazendo apenas ônus ao retorno, uma vez que o risco mínimo aceitável é atingido por cada uma das carteiras, independente de sua cardinalidade. Tal constatação entra em acordo com a fronteira eficiente proposta por [Markowitz 1952], onde o retorno e o risco possuem relação diretamente proporcional entre si, e inversamente proporcional à diversificação. Por tratar-se de um problema com perturbações, onde lida-se com a imprevisibilidade 
do comportamento humano, o efeito da diversificação em relação às previsões de 2011 fogem ao escopo deste trabalho.

Como trabalhos futuros, pode-se considerar modelos alternativos ao de Markowitz, como é o caso do modelo de desvio absoluto médio de [Konno e Yamazaki 1991], assim como desenvolver novas heurísticas para análise comparativa, tais como Busca Tabu, Simulated Annealing, GRASP, ou heurísticas híbridas, e também inserir novas estratégias para as heurísticas já abordadas. Também pode-se acoplar as heurísticas anteriormente citadas a métodos de inteligência computacional, como redes neurais, máquinas de vetor de suporte ou colônias de formigas, visando a formação de conjuntos de investimento por similaridade, explorando o conceito de risco diversificável juntamente a outros modelos econômicos como o CAPM desenvolvido por Sharpe.

\section{Referências}

Beale, E. M. L. e Forest, J. J. H. (1976). Global optimization using special ordered sets. Mathematical Programming, 10:52-69.

Bird, R. e Tippett, M. (1986). Naïve diversification and portfolio risk: A note. Management Science.

Bovespa (2012). Índice bovespa. http: / / www . bmfbovespa. com.br.

Chang, T.-J., Meade, N., Beasley, J. E., e Sharaiha, Y. M. (2000). Heuristics for cardinality constrained portfolio optimisation. Computers and Operations Research, 27:12711302 .

Coley, D. A. (1999). Introduction to Genetic Algorithms for Scientists and Engineers. World Scientific.

Corazza, M. e Favaretto, D. (2007). On the existence of solutions to the quadratic mixedinteger mean-variance portfolio selection problem. European Journal of Operational Research, 176:1947-1960.

Cura, T. (2009). Particle swarm optimization approach to portfolio optimization. Nonlinear Analysis: Real World Applications, 10:2396-2406.

Derigs, U. e Nickel, N.-H. (2003). Meta-heuristic based decision support for portfolio optimisation with a case study on tracking error minimization in passive portfolio management. OR Spectrum, 25:345-378.

Evans, J. L. e Archer, S. H. (1968). Diversification and the reduction of dispersion: An empirical analysis. Journal of finance, pp 761-767.

Freitas, E. T. e Ribeiro, C. O. (2009). Abordagem robusta ao problema de seleção de portfólio. Simpósio Brasileiro de Pesquisa Operacional.

Gen, M. e Cheng, R. (1997). Genetic Algorithms and Engineering Design. New York: Wiley.

Holland, J. H. (1975). Adaptation in Natural and Artificial Systems: An Introductory Analysis With Applications to Biology, Control, and Artificial Intelligence. SpringerVerlag. 
Junior, M. P. L., de Almeida, M. R., e Ferreira, R. J. P. (2011). Seleção de portfólios por meio de busca tabú híbrida: Modelo de média variância em lotes. Simpósio Brasileiro de Pesquisa Operacional.

Kellerer, H., Mansini, R., e Speranza, M. G. (1999). Selecting portfolios with fixed costs and minimum transaction lots. Annals of Operations Research, 99:877-304.

Konno, H. e Yamazaki, H. (1991). Mean-absolute deviation portfolio optimization model and its application to tokyo stock market. Management Science, 37(3):519-531.

Li, D., Sun, X., e Wang, J. (2006). Optimal lot solution to cardinality constrained meanvariance formulation for portfolio selection. Mathematical Finance, 16:83-101.

Lin, C. C. e Liu, T. Y. (2007). Genetic algorithms for portfolio selection problems with minimum transaction lots. European Journal of Operational Research. O.R. Applications.

Maringer, D. (2005). Portfolio management with heuristic optimization. Springer, The Netherlands.

Markowitz, H. M. (1952). Portfolio selection. Journal of Finance, 7(1):77-91.

Markowitz, H. M. (1959). Portfolio selection: Efficient diversification of investments. New York: Wiley.

Markowitz, H. M., Todd, P., Xu, G., e Yamane, Y. (1993). Computation of meansemivariance efficient sets by the critical line algorithm. Annals of Operations Research, 45:307-317.

Pham, D. T. e Karaboga, D. (2000). Intelligent Optimisation Techniques: Genetic Algorithms, Tabu Search, Simulated Annealing and Neural Networks. Springer.

Radcliffe, N. J. (1991). Forma analysis and random respectful recombination. Fourth International Conference on Genetic Algorithms, pp 222-229.

Raposo, R. C. T. (2010). Seleção de portfólios por meio de busca tabú híbrida: Modelo de média variância em lotes. Workshop de Inteligência Computacional Aplicada.

Sharpe, W. F. (1963). A simplified model for portfolio analysis. Management Science, pp 277-293.

Shaw, D. X., Liu, S., e Kopman, L. (2008). Lagrangian relaxation procedure for cardinality-constrained portfolio optimization. Optimization Methods and Software, 23:411-420.

Torre, N. G. e Rudd, A. (2004). The portfolio management problem of individual investors: A quantitative perspective. Institutional Investor's Guide to Integrated Wealth Management. 